\title{
Activation of Neutrophils by Nanoparticles
}

\author{
David M. Goncalves, Rafael de Liz, and Denis Girard \\ Laboratoire de Recherche en Inflammation et Physiologie des Granulocytes, INRS-Institut Armand-Frappier, \\ Université du Québec, Laval, QC, Canada H7V $1 B 7$
}

Received 23 July 2011; Accepted 23 August 2011

Academic Editor: Claude Ostiguy

The use of nanoparticles (NPs) has increased in the past few years in various fields, including defence, aerospace, electronics, biology, medicine, and so forth. and in applications such as diagnostic technology, bioimaging, and drug/gene delivery. Thus, human exposure to NPs and nanomaterials is unavoidable and will certainly expand in the future resulting in a growing interest in nanotoxicology, the study of toxicity of nanomaterials. A number of studies have reported the effects of NPs in respect to pulmonary inflammation by investigating in vitro activation of pulmonary cells with NPs and in vivo in a variety of models in which neutrophils appear to be the predominant leukocyte cell type in lungs and in bronchoalveolar lavages following inhalation or intratracheal instillation of NPs. Despite the fact that several studies have reported an increased number of neutrophils, the literature dealing with the direct activation of neutrophils by a given NP is poorly documented. This paper will summarize the current literature in this latter area of research and will end with a perspective view in which our laboratory will be involved in the following years.

KEYWORDS: inflammation, nanotoxicology, neutrophils, nanoparticles 


\section{FROM NANOBIOTECHNOLOGY TO NANOTOXICOLOGY}

The prefix "nano" is derived from the Greek "nanos" means "dwarf" and is becoming increasingly prevalent in scientific literature. The concept of nanotechnology itself is not recent and is usually attributed to a speech made by Dr. Richard Feynman, a well-known American physicist, at the December 1959 meeting of the American Physical Society where he asked: "What would happen if we could arrange the atoms one by one the way we want them? [1]. Research in the nanotechnology field is growing at breathtaking speed, and the reason is simple: nanomaterials are expected to improve virtually all types of products $[2,3]$. Nanoparticles (NPs) are defined as small-scale substances (at least one dimension $<100 \mathrm{~nm}$ ) with unique properties, whereas nanomaterials are defined as small-scale substances engineered to achieve unique mechanical, optical, electrical, and magnetic properties $[4,5]$. While emerging nanotechnologies have great potential for human needs, there is increasing concern that the same features that make them interesting also represent a menace to human health [6]. Consequently, a new branch of toxicology, nanotoxicology, has recently emerged. This field, which can be defined as the evaluation of safety of engineered nanostructures and nanodevices, is growing rapidly, since information about safety and potential hazards is urgently needed. Exposure to NPs has increased dramatically in the past few years due to anthropogenic sources given that NPs can be formed via a wide variety of processes/methods. These sources are numerous and include internal combustion engines, power plants, and many other sources of thermodegradation [7]. Furthermore, intense research and development by the industry and academia multiply the number of individuals potentially exposed to NPs.

Nanotoxicology is, therefore, a very complex discipline, and the diversity and complexity of NPs makes chemical characterization not only more important but also more difficult [8].

\section{INFLAMMATION: POSITIONING NEUTROPHILS}

Inflammation is a normal biological response of the body to various assaults, including microorganisms, injuries, dusts, drugs, and other chemicals. Under normal circumstances, inflammation will subside and resolve itself in an individual through a series of tightly regulated responses. However, when deregulation occurs, inflammation can lead to inflammatory disorders and diseases including asthma and several pulmonary lung diseases, dermatitis, arthritis, inflammatory bowel diseases, and so forth, [9, 10]. During acute inflammation, polymorphonuclear neutrophil cells (PMNs) are the first type of leukocytes to migrate to an inflammatory site, where they will produce several proinflammatory mediators including chemokines that first attract other PMNs and then other cell types like monocytes-macrophages and lymphocytes, corresponding to chronic inflammation.

PMNs are phagocytes well recognized for their ability to eliminate bacteria and fungi. These cells eliminate invading pathogens via two important mechanisms: (i) the respiratory burst, which is an oxygendependent process leading to the generation of reactive oxygen species (ROS) and (ii) degranulation, an oxygen-independent mechanism by which PMNs release potent toxic degradative products stored in granules. In addition to reactive oxygen metabolites and granule enzymes, PMNs are known to be an important source of products implicated in tissue damage and inflammation such as leukotriene $\mathrm{B}_{4}$, plateletactivating factor, and various cytokines (IL- $1 \alpha$, IL- 8 , IL- 12 , TNF- $\alpha$, TGF- $\beta$, and GRO- $\alpha$ ), to name a few [9]. The importance of PMNs in inflammation is further supported by the observation that various PMN priming and activating agents such as IL- $1 \beta$, IL-8, IL-15, GM-CSF, TGF- $\beta$, C5a, C9, and so forth, are present, for example, in the synovial fluids of rheumatic patients [11-13].

In humans, PMNs are the most abundant leukocytes in circulation, representing more than $65 \%$ of this blood cell population. They are terminally nondividing cells which develop in bone marrow. It has been estimated that about $5 \times 10^{10}$ cells/day are released from bone marrow into circulation in a normal adult $[14,15]$. Therefore, cell turnover must be under strict control in order to prevent diseases. The number of PMNs remains relatively constant in healthy individuals, and this is due to the limited lifespan (half-life of $\sim 12 \mathrm{~h}$ in circulation) of these cells and the fact that they spontaneously undergo apoptosis. Identification of 
pro- or antiapoptotic agents is of major importance, since resolution of inflammation occurs by elimination of apoptotic PMNs by professional phagocytes such as macrophages. When the rate of PMN apoptosis is accelerated, this results in an increase in bacterial susceptibility. In contrast, when apoptosis is delayed or suppressed, this can aggravate inflammation and lead to autoimmune disorders. It is important to mention that the same arsenal and biological responses of PMNs involved in host defence can also be deleterious for an organism when deregulation occurs. This phenomenon is known as the neutrophil paradox in which the defending cell becomes an enemy. Because of this, and knowing the role of PMNs during inflammation (PMNs are seen as conductors of inflammation), it is very important to carefully understand the mode of action of PMN agonists as well as to identify new ones. Of note, even if an agent is not a direct PMN agonist by itself, it can be indirectly proinflammatory by attracting these cells in vivo, as is the case with IL-21 $[16,17]$.

Curiously, despite the importance of PMNs in the inflammatory process and the fact that several studies have reported an increased number of PMNs in NPs-induced pulmonary inflammation, there are few studies investigating the effects and the mode of action of NPs on neutrophils. The following sections will cover different studies that has been done regarding the effects of some NPs on PMN cell physiology. Although the well accepted definition of a NP is a particle $<100 \mathrm{~nm}$, we will also discuss the role of particles greater than $100 \mathrm{~nm}$ in size, since the literature regarding the interaction between NPs and neutrophils is poorly documented.

\section{NEUTROPHIL ACTIVATION BY NANOPARTICLES: A REVIEW}

\subsection{Review of the Literature (the $80 \mathrm{~s}$ )}

One of the first studies investigating the interaction between NPs and neutrophils was done in 1988; Hedenborg published that titanium dioxide $\left(\mathrm{TiO}_{2}\right)$ dust induced the production of ROS by human neutrophils as measured by a chemiluminescence assay. Different dust particles (ranging in size from 345 to $1000 \mathrm{~nm}$ ) were tested, and none of them were cytotoxic, as assessed by lysozyme release or trypan blue exclusion [18]. It was concluded that $\mathrm{TiO}_{2}$ stimulated the chemiluminescence activity of PMNs in a concentration-dependent manner and that particle size and surface structure of the dust were important for determining the intensity of the response.

\subsection{Review of the Literature (the $90 \mathrm{~s}$ )}

In 1991, Papatheofanis and Barmada incubated human PMNs with increasing concentrations of polymethylmethacrylate (PMMA) NPs (50-60 nm) in vitro and found that this induced the release of lactate dehydrogenase, lysosome, and beta-glucuronidase in a dose-dependent fashion [19]. Conversely, they reported that PMMA NPs diminished migration of PMNs in a dose-dependent manner, as assessed by measuring the distance attained by the leading front of cells in Boyden chambers. Polystyrene beads ( $50 \mathrm{~nm}$ in diameter) were employed as a physical control in all experiments and, although they affected the tested functions when compared with cells incubated with buffer alone, the intensity of the response was always inferior to that of PMMA NPs.

Using solid lipid NPs (SLN) produced by high pressure homogenisation of melted lipids (glycerolbehenate, cetylpalmitate), Müller et al. reported in 1996 that modifying the surface of these NPs with hydrophilic poloxamine 908 and poloxamer 407 blockcopolymers generated slightly different results regarding the phagocytic uptake and cell viability of human PMNs [20]. Of note, the viability was always greater than $80 \%$ for all tested NPs ranging from a diameter of 123 to $246 \mathrm{~nm}$, as assessed by the colorimetric MTT (dimethylthiazolyl-diphenyltetrazolium) assay. Modification of the solid lipid NPs with poloxamine 908 and poloxamer 407 reduced phagocytic uptake by human PMNs to about 8-15\% of the phagocytic uptake of hydrophobic polystyrene particles. In another study conducted by Müller and collaborators [20], the in vitro cytotoxicity of SLN was investigated as a function of lipid matrix and stabilizing surfactant in 
human PMNs as well as in promyelocyte HL-60 cells. These latter cells, which can be differentiated toward neutrophil-like cells, were used for comparison with fully mature PMNs isolated from the blood of healthy volunteers, with the interest of using them to replace the daily isolation that is costly and time consuming. They found that the nature of the lipid had no effect on the cell viability in either PMNs or HL-60 cells, but that some distinct differences were found for the surfactants. For example, binding of poloxamer 184 to the SLN surface reduced the cytotoxicity of the surfactant by a factor of $\sim 65$. They concluded that HL-60 cells represented a potentially good model for replacement of primary PMNs, but, as it will discussed later, this is not always the case.

\subsection{Review of the Literature (Since 2000)}

Due to the increasing popularity of nanobiotechnologies land, the growing interest in nanotoxicology, a series of studies were conducted more recently. However, although several studies focussing on lung inflammation induced by NPs in animal models have reported that the presence of PMNs is increased, few studies have examined the role and mode of action of a given NP directly on PMNs.

\section{NONHUMAN NEUTROPHILS}

\subsection{Fish PMNs}

Two studies have used fish neutrophils to investigate the effect of hydroxylated fullerenes (h-fullerenes) and nanosized $\mathrm{TiO}_{2}[21,22]$. In these two studies (conducted by the same team), granulocytes were isolated from the kidneys of fathead minnows; more than $\sim 80 \%$ of cells were positive for myeloperoxidase (MPO), indicating that the vast majority of cells were of a myelopoietic lineage.

In the first study, h-fullerenes $(0.2-200 \mu \mathrm{g} / \mathrm{mL})$ were found to inhibit oxidative burst (carboxy$\mathrm{H}_{2}$ DFFDA probe) as well as degranulation of primary granules (MPO release) in a concentration-dependent fashion [22]. In addition, they reported that h-fullerenes induced NETosis or the release of NETs (neutrophil extracellular traps) in a bell-shaped concentration-response curve as assessed by quantification of DNA in the supernatants after $2 \mathrm{~h}$ of incubation. The maximum effect was observed at a concentration of $2 \mu \mathrm{g} / \mathrm{mL}$. The size distribution of the particles varied from 164 to $1990 \mathrm{~nm}$ in HBSS without $\mathrm{Ca}^{2+}, \mathrm{Mg}^{2+} ; 531$ to $111 \mathrm{~nm}$ in HBSS with $\mathrm{Ca}^{2+}$ and $\mathrm{Mg}^{2+}$; or 615 to $2300 \mathrm{~nm}$ in egg water. Some agglomerates composed of about $2-10$ NPs were confirmed by microscopic imaging. Interestingly, a bimodal distribution was observed when particle were dissolved in HBSS without $\mathrm{Ca}^{2+}$ and $\mathrm{Mg}^{2+}$ (one peak at 235 and one at $1370 \mathrm{~nm}$ ) while an unimodal distribution was observed in HBSS with $\mathrm{Ca}^{2+}$ and $\mathrm{Mg}^{2+}$ (peak at $814 \mathrm{~nm}$ ) and in egg water (peak at $1250 \mathrm{~nm}$ ). Although the toxicity of the NPs was tested in vivo and revealed no significant mortality in the minnows, there is no information regarding the potential cytotoxicity of the NPs to PMNs in vitro at the tested concentrations.

Similar experiments were conducted in the second study, except that fish PMNs were incubated with $\mathrm{TiO}_{2}$ NPs $(0.1-1000 \mu \mathrm{g} / \mathrm{mL})$ instead of h-fullerenes. They reported that $\mathrm{TiO}_{2}$ NPs also increased respiratory burst when used alone or in combination with PMA [21]. However, NETs release was not observed when cells were incubated with $\mathrm{TiO}_{2} \mathrm{NPs}$ alone but was noticed when incubated in combination with the classical neutrophil agonist phorbol 12-myristate 13-acetate (PMA). $\mathrm{TiO}_{2}$ NPs did not modulate degranulation when used alone or in preactivated cells. In another study, the size distribution of the $\mathrm{TiO}_{2} \mathrm{NPs}_{\text {sas evaluated. An }}$ unimodal distribution was observed in HBSS with or without $\mathrm{Ca}^{2+}$ and $\mathrm{Mg}^{2+}$ (peak at 66 and $88 \mathrm{~nm}$, resp.), while a multimodal distribution was observed in egg water, with three major peaks at 1,7 , and $75 \mathrm{~nm}$.

\subsection{Rat PMNs}

PMNs were harvested following induction of peritonitis and were then incubated in vitro with poly(lactide acid) NPs alone (PLA) or in combination with poly(ethylene glycol) PEG (PLA/PEG) at $250 \mu \mathrm{g} / \mathrm{mL}$. 
The production of ROS due to the oxidative burst of PMNs following phagocytosis of PLA or PLA/PEG was measured by chemiluminescence [23]. The mean diameter of the NPs was $266 \pm 15 \mathrm{~nm}, 328 \pm 9 \mathrm{~nm}$, and $374 \pm 3 \mathrm{~nm}$ for PLA, PLA/PEG $(1: 0.25)$, and PLA/PEG $(1: 1)$, respectively. Similar ROS production was observed when PMNs were activated by PLA or PLA/PEG $(1: 0.25)$, but lower production was observed by activation with PLA/PEG $(1: 1)$, probably due to the hydrophilic characteristics of PEG forming a solvated layer coating the NPs surface, as mentioned by the authors. Such a phenomenon would lead to decreased phagocytosis by preventing opsonization. Interestingly, analysis of phagocytosis by microscopy revealed that, unlike the positive control zymosan, in which $100 \%$ of cells were activated, as evidenced by the appearance of large intracellular vacuoles in PMNs, only $50 \%$ of cells were activated by PLA or PLA/PEG $(1: 1)$.

\subsection{Human PMNs}

In 2002, Kumazawa and colleagues, using titanium (Ti), vanadium (V), and nickel (Ni) particles at 2 and $10 \mathrm{ppm}$, investigated neutrophil responses [24]. In solution, only Ni was found to decrease cell survival rate (trypan blue exclusion) and to increase the release of lactate dehydrogenase (LDH). Unlike Ni, both Ti and V particles stimulated PMNs to increase superoxide $\left(\mathrm{O}_{2}{ }^{-}\right)$production, as assessed by the ferrocytochrome reduction assay. The amount of TNF- $\alpha$ released by PMNs was measured by ELISA and was only increased by small Ti particles (diameter of $1-3 \mu \mathrm{m}$ ) whereas this effect was not observed when the particle size was larger $(10 \mu \mathrm{m})$. Using scanning electron microscopy, they showed that only $\mathrm{Ni}$ in solution destroyed the cell membrane of PMNs. They also reported that only Ti particles $(1-3 \mu \mathrm{m})$ in solution were engulfed by PMNs. This is one of the first studies reporting that the cytotoxicity of a particle (Ti) is size dependent and that PMN functions are modulated differently by the size of particles.

Memisoglu-Bilensoy et al. [25] determined the cytotoxicity of injectable cyclodextrin nanoparticles/ nanocapsules (specifically, $\beta$-CDC6) against mouse L929 fibroblasts and human PMNs. The objective was to evaluate their cytotoxicity with or without the presence of PF68, the most commonly used surfactant in NPs formulations and which is designed to be potentially utilized as an injectable nanosized drug carrier. Depending on the formulation, the particle size distribution was between $\sim 110$ and $350 \mathrm{~nm}$. The cytotoxicity was determined using the MTT assay, and the authors concluded that $\beta$-CDC6 NPs do not exert a significant cytotoxicity against fibroblasts nor PMNs. However, although the experimental conditions, in which cells were incubated for 3 days before performing the assay, were appropriate for fibroblasts, this was not necessarily the same for PMNs, since these cells are known to spontaneously undergo apoptosis when incubated in vitro (about 50\% of PMNs are in apoptosis after only $24 \mathrm{~h}$ ) [26, 27].

The interaction between cholesteryl butyrate (chol-but) solid lipid NPs and PMNs was investigated by Dianzani and colleagues [28]. In vitro incubation of PMNs with $10^{-8}-10^{-4} \mathrm{M}$ cholesteryl-butyrate solid lipid nanoparticles (chol-but SLN, mean diameter of 130-160 nm) for a period of time ranging from 10 to 240 min did not lead to cytotoxic effects as measured by trypan blue exclusion [28]. Also, chol-but SLN were found to inhibit adhesion of PMNs onto foetal calf serum-coated plastic wells as well as onto human umbilical vein endothelial cells. Finally, in this study, the ability of FMLP-induced $\mathrm{O}_{2}{ }^{-}$production and FLMP-induced MPO release by PMNs was rapidly inhibited by chol-but SLN treatment.

More recently, the capacity of human immune cells to internalize rod-shaped and spherical gold NPs (AuNPs), with diameters ranging between 15 and $50 \mathrm{~nm}$ and a variety of surface chemistries, has been determined. In contrast to monocytes-macrophages that ingest AuNPs [29], PMNs were found to trap them in their extracellular structures, the NETs being composed mainly of DNA and a variety of antibacterial proteins [30]. Interestingly, the cell-gold networks, visible after as early as 15 min of treatment of immune cells with the AuNPs, were predominantly observed in PMNs and, to a lesser extent, in monocytes and macrophages. Such a mechanism indicates that NETs act as a physical barrier for NPs. In addition, in this study, Bartneck et al. demonstrated that particle shape is not very important for particle trapping whereas the positive charges significantly enhance this phenomenon [30].

Our laboratory has been interested in investigating the role of NPs in various human PMN functions, rather than focussing on only one (or very few) function, in order to get a more generalized picture on the 
mode of action of NPs on PMNs cell physiology [31]. $\mathrm{TiO}_{2}$ NPs were selected for our first study since it is presently the most studied NP reported in the literature. We used a commercially available preparation of $\mathrm{TiO}_{2} \mathrm{NPs}$ (anatase crystals) of 1-10 $\mathrm{nm}(90 \%)$ in size, as determined by transmission electronic microscopy (mentioned in the technical data sheet and also confirmed by us). We first incubated freshly isolated human PMNs with increasing concentrations of $\mathrm{TiO}_{2}$ NPs $(0-800 \mu \mathrm{g} / \mathrm{mL})$ over time and determined if the NPs were cytotoxic. As assessed by trypan blue exclusion, the NPs did not decrease cell viability and only a small portion of about $1-3 \%$ of cells were typically in necrosis after $24 \mathrm{~h}$ of incubation at the highest concentration tested. Next, we determined whether or not $\mathrm{TiO}_{2} \mathrm{NPs}$ could induce morphological changes. After $24 \mathrm{~h}$, the optimal concentration inducing cell shape changes was $100 \mu \mathrm{g} / \mathrm{mL}$, a concentration used by others with human lymphocytes [32]. Of note, others reported the use of $\mathrm{TiO}_{2} \mathrm{NPs}$ at up to $4000 \mu \mathrm{g} / \mathrm{mL}$ for evaluating apoptosis in U937 human monoblastoid cell line [33]. Next, we found that $\mathrm{TiO}_{2} \mathrm{NPs}$ induced rapid phosphorylation events in PMNs as quickly as 15 seconds, with a maximal effect at 1 minute of treatment, as assessed by monitoring phosphotyrosine residues. More specifically, we identified Erk-1/2 and p38 MAP kinases, two major enzymes involved in different PMNs functions, as targets of $\mathrm{TiO}_{2}$ NPs. In accordance with the above results demonstrating that the NPs are not cytotoxic, we reported in this study that they significantly inhibited PMN apoptosis at 50 and $100 \mu \mathrm{g} / \mathrm{mL}$. Using an antibody array allowing the simultaneous detection of 36 different cytokines/chemokines, $\mathrm{TiO}_{2} \mathrm{NPs}$ were found to induce the production of 13 analytes, including IL- 8 and Gro- $\alpha$, which exhibited the greatest increase $(\sim 16$ times and $\sim 4$ times the levels of control cells, resp.). An ELISA assay allowed us to quantify that the NPs induced the production of more than $1200 \mathrm{pg} / \mathrm{mL}$ of IL-8 in the supernatants of $\mathrm{TiO}_{2}$-induced PMNs.

\section{PERSPECTIVES}

The studies discussed above have focussed mainly on in vitro activity of a given NP on neutrophils. Most of these studies evaluated the cytotoxicity and/or only one or few PMN responses. No study other than our own has determined the PMN apoptotic rate in response to NPs. However, more recent reports have investigated the interaction between NPs and PMNs by studying several different functions/responses, an approach that we encourage. For example, the fact that we found that $\mathrm{TiO}_{2} \mathrm{NPs}$ can induce the production of several analytes, including two potent chemokines (IL-8 and Gro- $\alpha$ ), indicates that NPs can target PMNs that, in turn, could activate other cells [31]. We suspect that, in the forthcoming years, this area of research will become more significant and more studies will be pursued. We also believe that, in addition to investigating the mode of action of NPs in PMNs in vitro, it will be critical to determine the role of NPs in ex vivo experiments in animal models. Furthermore, determining if a given NP is proinflammatory or not in vivo in other models than those exclusively targeting the lungs will help us better evaluate the potential toxic mechanisms of NPs. Using the murine air pouch model, we have recently demonstrated that administration of a single dose of $\mathrm{TiO}_{2}$ NPs into the air pouch can attract leukocytes after 3-9 h, where more than $80 \%$ of cells are PMNs [34]. In addition, in this study, we reported that $\mathrm{TiO}_{2} \mathrm{NPs}$ induced the production of several chemokines locally present in the murine air pouch exudates. This model is a simple model that allowed us to investigate an acute inflammatory response, the first step leading to chronic inflammation when deregulation occurs, such as the many studies reporting an increased number of PMNs in lung/BALS [35-42]. On the other hand, the fact that a NP possesses some proinflammatory properties could be of help for the design of drug delivery by NPs for clinical purposes. In this regards, one can imagine attracting leukocytes such as PMNs into an inflammatory site by a NP delivering (or coated with) a neutrophil proapoptotic molecule. Although this is speculative at the moment, this remains an interesting avenue of research that needs to be explored in the future.

Information on how a NP with a different size or form will differently activate PMNs is of interest, as is the ability (or not) of PMNs to ingest NPs. Recently, Kagan et al. demonstrated that carbon nanotubes degraded by neutrophil MPO were found to be less proinflammatory in a model of pulmonary inflammation [42]. This is one example indicating the importance of investigating the interaction between NPs and PMNs. 
Our laboratory will investigate the direct effect of several distinct NPs on human PMN cell physiology in vitro. Using primary human cells for these studies is certainly more expensive and time consuming than using cell lines, since we have to isolate PMNs daily from blood donors, but the results are more easily interpretable for the evaluation of human risk. Furthermore, the two major human cell lines that can be driven by chemical treatment into "neutrophils-like cells," the HL-60 and PLB-985 cell lines, are not real PMNs and can respond differently than PMNs $[43,44]$. Although we will investigate the immunomodulatory properties of a given NP on different PMNs functions in vitro, we will also determine cell signalling pathways involved as well as identify the nature of some PMN proteins that will be targets to NPs. This will be of great help for the elucidation of the mode of action of the tested NPs. In addition, we will pursue investigating the proinflammatory effect of NPs using the murine air pouch model [34] as a simple reliable model of acute inflammation. For example, in addition to the identification of cytokines/chemokines and leukocyte populations in kinetic and concentration-dependent experiments, this will lead to a classification of different NPs according to their degree of proinflammatory properties.

\section{ABBREVIATIONS}

$\begin{array}{ll}\text { NP: } & \text { Nanoparticle } \\ \text { PMNs: } & \text { Polymorphonuclear neutrophil cells } \\ \text { ROS: } & \text { Reactive oxygen species } \\ \mathrm{TiO}_{2}: & \text { Titanium dioxide } \\ \text { PMMA: } & \text { Polymethylmethacrylate } \\ \text { SLN: } & \text { Solid lipid NPs } \\ \text { MTT: } & \text { Dimethylthiazolyl-diphenyltetrazolium } \\ \text { h-fullerenes: Hydroxylated fullerenes } \\ \text { MPO: } & \text { Myeloperoxidase } \\ \text { NETs: } & \text { Neutrophil extracellular traps } \\ \text { PLA: } & \text { Poly-lactide acid } \\ \text { PEG: } & \text { Polyethylene glycol } \\ \text { LDH: } & \text { Lactate dehydrogenase } \\ \mathrm{O}_{2}{ }^{-}: & \text {Superoxide } \\ \text { Chol-but: } & \text { Cholesteryl-butyrate. }\end{array}$

\section{ACKNOWLEDGMENTS}

This study was supported by the Institut de recherche Robert-Sauvé en santé et en sécurité du travail (IRSST). D. M. Goncalves holds a Ph.D. degree in natural sciences and Engineering Research Council of Canada (NSERC) Award and R. de Liz holds a doctoral award from the Brazilian government for a training abroad. The authors thank Mary Gregory for reading this paper.

\section{REFERENCES}

[1] C. Buzea, I. I. Pacheco, and K. Robbie, "Nanomaterials and nanoparticles: sources and toxicity," Biointerphases, vol. 2, pp. 17-71, 2007.

[2] The Royal Society, "Nanoscience and nanotechnologies: opportunities and uncertainties," 2004, page 127.

[3] C. Ostiguy, "IRSST-Les effets à la santé reliés aux nanoparticules (Montréal: institut de Recherche Robert-Sauvé en santé et sécurité au travail )," 2006, page 155.

[4] T. J. Webster, "Safety of Nanoparticles: From Manufacturing to medical applications," 2009, Providence, RI, USA.

[5] J. S. Tsuji, A. D. Maynard, P. C. Howard et al., "Research strategies for safety evaluation of nanomaterials, part IV: risk assessment of nanoparticles," Toxicological Sciences, vol. 89, no. 1, pp. 42-50, 2006. 
[6] A. D. Maynard, "Nanotechnology: the next big thing, or much ado about nothing?" Annals of Occupational Hygiene, vol. 51, no. 1, pp. 1-12, 2007.

[7] G. Oberdörster, E. Oberdörster, and J. Oberdörster, "Nanotoxicology: an emerging discipline evolving from studies of ultrafine particles," Environmental Health Perspectives, vol. 113, no. 7, pp. 823-839, 2005.

[8] EPA-Nanotechnology-White-Paper, "Nanotechnology White Paper. U.S.E.P.A. (EPA),” 2007, page 120.

[9] S. W. Edwards and M. B. Hallett, "Seeing the wood for the trees: the forgotten role of neutrophils in rheumatoid arthritis," Immunology Today, vol. 18, no. 7, pp. 320-324, 1997.

[10] A. P. Watt, B. C. Schock, and M. Ennis, "Neutrophils and eosinophils: clinical implications of their appearance, presence and disappearance in asthma and COPD," Current Drug Targets, vol. 4, no. 4, pp. 415-423, 2005.

[11] L. Ottonello, G. Frumento, N. Arduino et al., "Delayed neutrophil apoptosis induced by synovial fluid in rheumatoid arthritis: role of cytokines, estrogens, and adenosine," Annals of the New York Academy of Sciences, vol. 966, pp. 226-231, 2002.

[12] O. J. Cordero, F. J. Salgado, A. Mera-Varela, and M. Nogueira, "Serum interleukin-12, interleukin-15, soluble CD26, and adenosine deaminase in patients with rheumatoid arthritis," Rheumatology International, vol. 21, no. 2, pp. 69-74, 2001.

[13] G. Steiner, M. Tohidast-Akrad, G. Witzmann et al., "Cytokine production by synovial T cells in rheumatoid arthritis," Rheumatology, vol. 38, no. 3, pp. 202-213, 1999.

[14] C. Ward, I. Dransfield, E. R. Chilvers, C. Haslett, and A. G. Rossi, "Pharmacological manipulation of granulocyte apoptosis: potential therapeutic targets," Trends in Pharmacological Sciences, vol. 20, no. 12, pp. 503-509, 1999.

[15] S. W. Edwards and F. Watson, "The cell biology of phagocytes," Immunology Today, vol. 16, no. 11, pp. 508-510, 1995.

[16] M. Pelletier, A. Bouchard, and D. Girard, "In vivo and in vitro roles of IL-21 in inflammation," Journal of Immunology, vol. 173, no. 12, pp. 7521-7530, 2004.

[17] M. Pelletier and D. Girard, "Biological functions of interleukin-21 and its role in inflammation," TheScientificWorldJournal, vol. 7, pp. 1715-1735, 2007.

[18] M. Hedenborg, "Titanium dioxide induced chemiluminescence of human polymorphonuclear leukocytes," International Archives of Occupational and Environmental Health, vol. 61, no. 1-2, pp. 1-6, 1988.

[19] F. J. Papatheofanis and R. Barmada, "Polymorphonuclear leukocyte degranulation with exposure to polymethylmethacrylate nanoparticles," Journal of Biomedical Materials Research, vol. 25, no. 6, pp. 761-771, 1991.

[20] R. H. Müller, S. Maaßen, H. Weyhers, and W. Mehnert, "Phagocytic uptake and cytotoxicity of solid lipid nanoparticles (SLN) sterically stabilized with poloxamine 908 and poloxamer 407," Journal of Drug Targeting, vol. 4, no. 3, pp. 161-170, 1996.

[21] B. Jovanović, L. Anastasova, E. W. Rowe, Y. Zhang, A. R. Clapp, and D. Palić, "Effects of nanosized titanium dioxide on innate immune system of fathead minnow (Pimephales promelas Rafinesque, 1820)," Ecotoxicology and Environmental Safety, vol. 74, no. 4, pp. 675-683, 2011.

[22] B. Jovanović, L. Anastasova, E. W. Rowe, and D. Palić, "Hydroxylated fullerenes inhibit neutrophil function in fathead minnow (Pimephales promelas Rafinesque, 1820)," Aquatic Toxicology, vol. 101, no. 2, pp. 474-482, 2011.

[23] R. M. Mainardes, M. P. D. Gremião, I. L. Brunetti, M. D. Luiz Fonseca, and N. M. Khalil, "Pharmaceutical nanotechnology zidovudine-loaded PLA and PLA-PEG blend nanoparticles: influence of polymer type on phagocytic uptake by polymorphonuclear cells," Journal of Pharmaceutical Sciences, vol. 98, no. 1, pp. 257-267, 2009.

[24] R. Kumazawa, F. Watari, N. Takashi, Y. Tanimura, M. Uo, and Y. Totsuka, "Effects of Ti ions and particles on neutrophil function and morphology," Biomaterials, vol. 23, no. 17, pp. 3757-3764, 2002.

[25] E. Memisoglu-Bilensoy, A. L. Doğan, and A. A. Hincal, "Cytotoxic evaluation of injectable cyclodextrin nanoparticles," Journal of Pharmacy and Pharmacology, vol. 58, no. 5, pp. 585-589, 2006.

[26] R. Duffin, A. E. Leitch, S. Fox, C. Haslett, and A. G. Rossi, "Targeting granulocyte apoptosis: mechanisms, models, and therapies," Immunological Reviews, vol. 236, no. 1, pp. 28-40, 2010.

[27] V. Lavastre, M. Pelletier, R. Saller, K. Hostanska, and D. Girard, "Mechanisms involved in spontaneous and Viscum album agglutinin-I-induced human neutrophil apoptosis: viscum album agglutinin-I accelerates the loss of antiapoptotic Mcl-1 expression and the degradation of cytoskeletal paxillin and vimentin proteins via caspases," Journal of Immunology, vol. 168, no. 3, pp. 1419-1427, 2002.

[28] C. Dianzani, R. Cavalli, G. P. Zara et al., "Cholesteryl butyrate solid lipid nanoparticles inhibit adhesion of human neutrophils to endothelial cells," British Journal of Pharmacology, vol. 148, no. 5, pp. 648-656, 2006. 
[29] M. Bartneck, H. A. Keul, S. Singh et al., "Rapid uptake of gold nanorods by primary human blood phagocytes and immunomodulatory effects of surface chemistry," ACS Nano, vol. 4, no. 6, pp. 3073-3086, 2010.

[30] M. Bartneck, H. A. Keul, Z. K. Gabriele, and J. Groll, "Phagocytosis independent extracellular nanoparticle clearance by human immune cells," Nano Letters, vol. 10, no. 1, pp. 59-64, 2010.

[31] D. M. Gonçalves, S. Chiasson, and D. Girard, "Activation of human neutrophils by titanium dioxide (TiO2) nanoparticles," Toxicology in Vitro, vol. 24, no. 3, pp. 1002-1008, 2010.

[32] S. J. Kang, B. M. Kim, Y. J. Lee, S. H. Hong, and H. W. Chung, "Titanium dioxide nanoparticles induce apoptosis through the JNK/p38-caspase-8-Bid pathway in phytohemagglutinin-stimulated human lymphocytes," Biochemical and Biophysical Research Communications, vol. 386, no. 4, pp. 682-687, 2009.

[33] C. I. Vamanu, M. R. Cimpan, P. J. Høl, S. Sørnes, S. A. Lie, and N. R. Gjerdet, "Induction of cell death by TiO2 nanoparticles: studies on a human monoblastoid cell line," Toxicology in Vitro, vol. 22, no. 7, pp. 1689-1696, 2008.

[34] D. M. Goncalves and D. Girard, "Titanium dioxide (TiO(2)) nanoparticles induce neutrophil influx and local production of several pro-inflammatory mediators in vivo," International Immunopharmacology, vol. 11, no. 8, pp. 1109-1115, 2011.

[35] A. Srinivas, P. J. Rao, G. Selvam, P. B. Murthy, and P. N. Reddy, "Acute inhalation toxicity of cerium oxide nanoparticles in rats," Toxicology Letters, vol. 205, no. 2, pp. 105-115, 2011.

[36] C. M. Sayes, K. L. Reed, and D. B. Warheit, "Nanoparticle toxicology: measurements of pulmonary hazard effects following exposures to nanoparticles," Methods in Molecular Biology, vol. 726, pp. 313-324, 2011.

[37] S. Hussain, J. A.J. Vanoirbeek, K. Luyts et al., "Lung exposure to nanoparticles modulates an asthmatic response in a mouse model," European Respiratory Journal, vol. 37, no. 2, pp. 299-309, 2011.

[38] M. Roursgaard, S. S. Poulsen, L. K. Poulsen et al., "Time-response relationship of nano and micro particle induced lung inflammation. Quartz as reference compound," Human and Experimental Toxicology, vol. 29, no. 11, pp. 915-933, 2010.

[39] E. M. Rossi, L. Pylkkänen, A. J. Koivisto et al., "Airway exposure to silica-coated TiO2 nanoparticles induces pulmonary neutrophilia in mice," Toxicological Sciences, vol. 113, no. 2, pp. 422-433, 2009.

[40] S. T. Larsen, M. Roursgaard, K. A. Jensen, and G. D. Nielsen, "Nano titanium dioxide particles promote allergic sensitization and lung inflammation in mice," Basic and Clinical Pharmacology and Toxicology, vol. 106, no. 2, pp. 114-117, 2010.

[41] N. R. Jacobsen, P. Møller, K. A. Jensen et al., "Lung inflammation and genotoxicity following pulmonary exposure to nanoparticles in ApoE-/-mice," Particle and Fibre Toxicology, vol. 6, article 2, 2009.

[42] V. E. Kagan, N. V. Konduru, W. Feng et al., "Carbon nanotubes degraded by neutrophil myeloperoxidase induce less pulmonary inflammation,” Nature Nanotechnology, vol. 5, no. 5, pp. 354-359, 2010.

[43] M. Pelletier, A. Savoie, and D. Girard, "Activation of human neutrophils by the air pollutant sodium sulfite (NA2SO3): comparison with immature promyelocytic HL-60 and DMSO-differentiated HL-60 cells reveals that NA2SO3 is a neutrophil but not a HL-60 cell agonist," Clinical Immunology, vol. 96, no. 2, pp. 131-139, 2000.

[44] C. Ratthé and D. Girard, "Investigation of the interleukin (IL)-4/IL-4 receptor system in promyelocytic leukaemia PLB-985 cells during differentiation toward neutrophil-like phenotype: mechanism involved in IL-4-induced SOCS3 protein expression," British Journal of Haematology, vol. 140, no. 1, pp. 59-70, 2008.

\section{This article should be cited as follows:}

David M. Goncalves, Rafael de Liz, and Denis Girard, "Activation of Neutrophils by Nanoparticles," TheScientificWorldJOURNAL, vol. 11, pp. 1877-1885, 2011. 

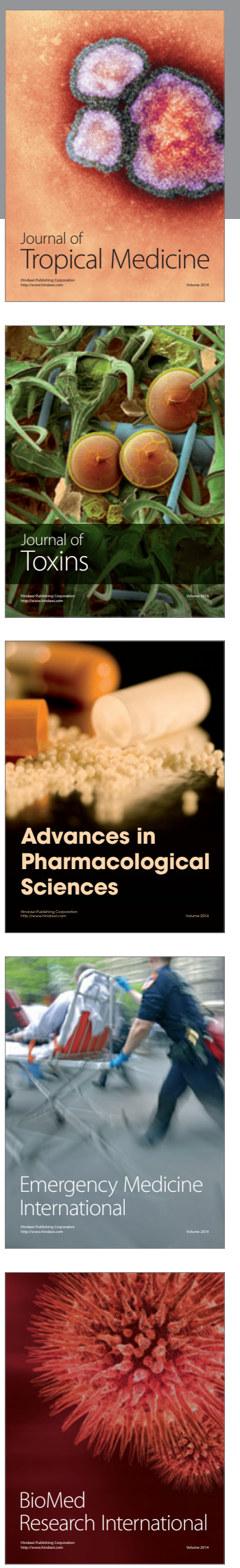
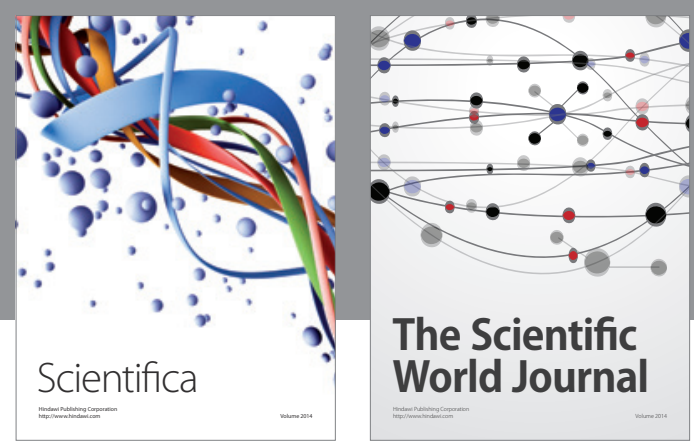

The Scientific World Journal
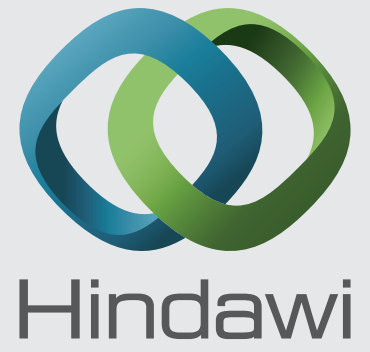

Submit your manuscripts at

http://www.hindawi.com
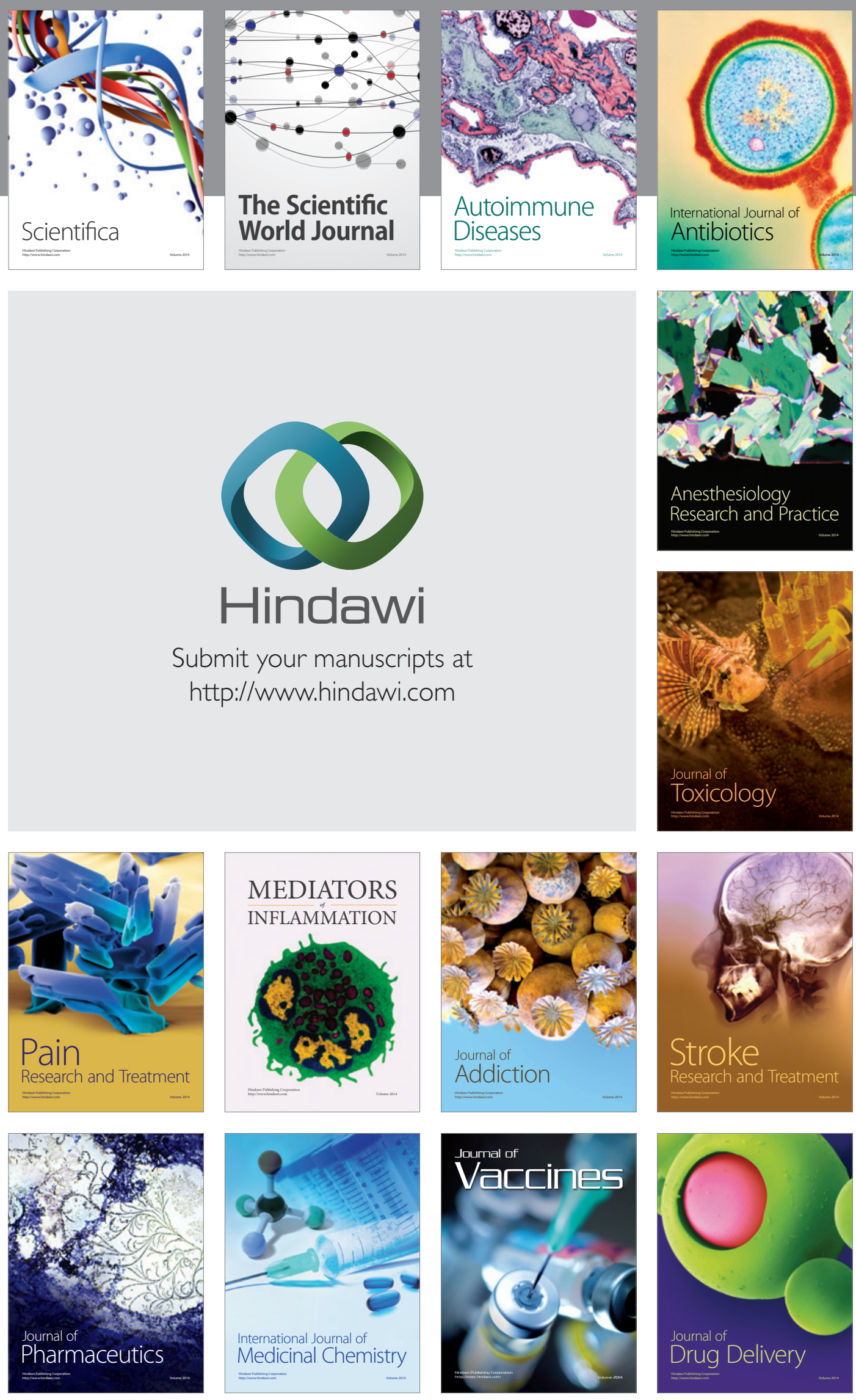